$\begin{array}{ll} & \text { Etnográfica } \\ \text { etnográfica } & \text { Revista do Centro em Rede de Investigação em }\end{array}$

Antropologia

vol. 19 (1) | 2015

Vol. $19(1)$

\title{
Geração, presença e memória: a Igreja Tocoísta em Angola
}

Generation, presence and memory: the Tokoist Church in Angola

\section{Ruy Llera Blanes e Ramon Sarró}

\section{(2) OpenEdition}

Journals

\section{Edição electrónica}

URL: https://journals.openedition.org/etnografica/3948

DOI: 10.4000/etnografica.3948

ISSN: 2182-2891

\section{Editora}

Centro em Rede de Investigação em Antropologia

\section{Edição impressa}

Data de publição: 1 fevereiro 2015

Paginação: 169-187

ISSN: 0873-6561

\section{Refêrencia eletrónica}

Ruy Llera Blanes e Ramon Sarró, «Geração, presença e memória: a Igreja Tocoísta em Angola», Etnográfica [Online], vol. 19 (1) | 2015, posto online no dia 06 março 2015, consultado o 09 fevereiro 2022. URL: http://journals.openedition.org/etnografica/3948 ; DOI: https://doi.org/10.4000/ etnografica.3948



Etnográfica is licensed under a Creative Commons Attribution-NonCommercial 4.0 International License. 


\section{Geração, presença e memória: a Igreja Tocoísta em Angola}

\section{Ruy Llera Blanes e Ramon Sarró}

Este artigo discute, a partir do estudo de caso da Igreja Tocoísta, a dialética entre processos de "presença" e "ausência" em movimentos proféticos em Angola e na diáspora angolana. Retoma algumas teses clássicas de Max Weber sobre carisma e rotinização da liderança para explicar, em função das dialéticas entre presença/ ausência e geração/memória, os processos de transformação ocorridos nesta igreja no contexto da Angola de pós-guerra.

PALAVRAS-CHAVE: profetismo, Angola, tocoísmo, memória, geração, presença.

Generation, presence and memory: the Tokoist Church in Angola - This article discusses, from the case study of the Tokoist Church, the dialectic between processes of "presence" and "absence" in prophetic movements in Angola and the Angolan diaspora. It revisits classic Weberian theses on charisma and routinization of leadership, in order to explain, through the dialectics of presence/absence and generation/memory, the transformations experienced in this church in post-war Angola.

KEYWORDS: prophetism, Angola, Tokoism, memory, generation, presence.

BLANES, Ruy Llera (ruy.blanes@gmail.com) - Department of Social Anthropology, University of Bergen, Noruega; Instituto de Ciências Sociais, Universidade de Lisboa, Portugal.

SARRÓ, Ramon (ramon.sarro@anthro.ox.ac.uk) - ISCA (Institute of Social and Cultural Anthropology), University of Oxford, Reino Unido. 


\section{INTRODUÇÃO: SOBRE PROFETISMO E CARISMA EM ANGOLA}

Desde as teorias inaugurais de Max Weber (2006) que a antropologia da religião se confronta sistematicamente com o problema da sucessão carismática (Blanes 2010), que por sua vez frequentemente se cruza, no contexto africano por exemplo, com o da sucessão política (Goody 1966). ${ }^{1}$ Como é que se reproduz um atributo tão pessoal como o carisma? Para muitos autores na esteira de Weber, o carisma não é reproduzível, mas é alvo de processos de rotinização, burocratização. A communitas emergida em volta de um líder carismático não é passível de recriação, mas converte-se numa estrutura política organizada a partir de diretrizes supostamente ditadas pelo líder desaparecido.

Não propondo necessariamente uma correção às teorias precursoras de Weber, neste artigo gostaríamos de sugerir, utilizando novamente a terminologia weberiana, que o carisma e a rotinização apenas são oponíveis enquanto "tipos ideais" através dos quais podemos pensar realidades bem mais flutuantes. Nem ninguém é 100\% puramente carismático sem qualquer tipo de burocratização em seu redor, nem ninguém é puramente burocrata sem incorporar qualquer tipo de carisma. Por exemplo, o papa do Vaticano pode aparecer-nos como puramente burocrático, no entanto para os crentes católicos a sua presença estabelece uma conexão direta com Jesus Cristo, explicada (ou talvez não explicada) através da noção teológica de "mistério". Para os seguidores da Igreja Kimbanguista - uma das igrejas proféticas que, juntamente com a Tocoísta, temos vindo a estudar desde 2006 (Sarró, Blanes e Viegas 2008; Sarró e Blanes 2009) -, Simon Kimbangu Kiangani, o atual líder, é uma nova personificação do seu avô Simon Kimbangu, o célebre profeta que morreu numa prisão do Congo Belga em 1951, após 30 anos de cárcere (ver Martin 1974; MacGaffey 1983). Isto apesar de, para muitos analistas externos, o mesmo líder poder parecer mais um tecnocrata gestor de uma empresa que a personificação do Espírito Santo.

I Este texto resulta de uma pesquisa em curso, desenvolvida em África e Portugal por Sarró e Blanes desde 2007, sobre movimentos proféticos africanos e a sua instalação na Europa. Estas pesquisas têm sido desenvolvidas no âmbito de três projetos de investigação: o projeto "O Atlântico cristão: etnografias de encontros religiosos entre igrejas africanas, brasileiras e portuguesas em Lisboa”, financiado pela Fundação para a Ciência e a Tecnologia (FCT, Portugal); o projeto "Recognizing Christianity: how African immigrants shape the European religious heritage" (2007-2010), coordenado (tal como o primeiro) por Ramon Sarró e financiado pela rede europeia NORFACE (consórcio de agências de financiamento estatais europeias, entre as quais a FCT portuguesa); e finalmente os projetos de investigação pós-doutoral do Ruy Blanes, "Pluralismo cristão: cristianismos africanos em Lisboa" (2007-2010) e "Religious knowledge and rationality in African prophetic churches", igualmente financiados pela FCT e desenvolvidos em parceria com a Universidade de Leiden, Holanda, onde esteve como guest researcher (2007-2010), e com a London School of Economics, onde esteve como visiting fellow (2010-2013). Agradecemos o feedback de Jorge Varanda, coordenador deste dossiê, e dos pareceristas, que nos ajudaram a melhorar sobremaneira o texto. 
Neste artigo, portanto, pretendemos cruzar o contínuo carisma-rotina utilizando outro que acabámos de invocar implicitamente: o da presença-ausência. Simultaneamente, sugeriremos que os temas da presença-ausência e da sucessão carismática estão intrinsecamente ligados a um terceiro - este sim estudado sistematicamente por antropólogos africanistas (ver Sarró 2009): o da idade e geração. Noutras palavras, seguimos a sugestão de Matthew Engelke (2007) ao considerar a "ausência" como um problema experiencial e politicamente central em movimentos religiosos estruturados em torno de uma liderança carismática; quando esta é "removida", desenvolvem-se múltiplas tecnologias de intermediação, "i-mediação" e "presentificação" (Eisenlohr 2009) que poderão - ou não - colmatar, resolver o problema da ausência. Essas tecnologias podem, por sua vez, incorporar e revelar processos ideológicos, políticos, estéticos e/ou experienciais.

Focamo-nos no caso particular da Igreja Tocoísta, uma igreja que se desenvolveu ao longo do século XX em Angola, embora, significativamente, tenha nascido no Congo Belga em 1949.2 À semelhança de outros movimentos, como a Igreja Kimbanguista, a Igreja Tocoísta, embora nascida no contexto de movimentos de resistência aos projetos coloniais europeus na região do Congo, constitui um exemplo relevante de vitalidade e agência no que se refere à persistência e transnacionalização de movimentos religiosos "meridionais" (Jenkins 2002; Robbins 2004; Mary 2008), encontrando-se representada não só em Angola e países circundantes na África Subsariana, mas também em vários países europeus e, mais recentemente, no Brasil. No contexto específico angolano, apesar da inexistência de números oficiais que o comprovem (ver Viegas 2007), é referida como sendo a segunda maior igreja cristã no país - estimando-se que tenha acima de um milhão de seguidores -, uma das poucas com um alcance por todo o território angolano e a única identificada unanimemente como sendo de "raiz autóctone". Para nós, esta igreja é particularmente interessante, quase paradigmática, no que diz respeito ao estudo de soluções autóctones perante o problema da sucessão carismática, já que, embora fosse complexo classificar Simão Toco na mesma categoria de líder onde colocaríamos Simon Kimbangu ou outros profetas africanos (em muitos aspetos Toco aproxima-se mais a um reformador como Lutero, embora noutros seja identificado com características mais proféticas e/ou messiânicas - ver Blanes 201 la), também é verdade que partilha com os profetas tidos como mais "clássicos" essa forte vinculação da sua obra à sua presença.

A Igreja Tocoísta (oficialmente, "Igreja do Nosso Senhor Jesus Cristo no Mundo, Relembrada a 25 de Julho de 1949 pela Sua Santidade o Profeta Simão Gonçalves Toco") é um movimento cristão profético de raízes batistas 
cujas principais características teológicas incluem o seguimento das profecias do seu fundador Simão Toco, a crença no carisma e no poder da visão e profecia. Igualmente, assenta de modo particular numa noção reformista de "relembrança", através da qual estabelece um distanciamento tanto de doutrinas cristãs de origem europeia e cristã como de tradições animistas e espiritistas africanas. Esta igreja nasceu em 1949, após a descida do Espírito Santo ao seu líder fundador e profeta, Simão Gonçalves Toco, em Léopoldville (no então Congo Belga). Apesar de este acontecimento ter tido lugar no Congo, o facto de Toco e seus seguidores serem emigrantes angolanos naquela cidade levou a que, depois da sua expulsão da colónia belga em 1950 (ver Blanes 2009a, 2009b, 2014), se desenvolvesse essencialmente em território angolano, onde o movimento viria a ser novamente perseguido pelas autoridades coloniais (neste caso a PIDE), que prenderam, torturaram, exilaram e forçaram Toco e as centenas de pessoas que o seguiram desde Léopoldville a trabalhos forçados. Este registo repressor, no entanto, não impediu que o movimento se expandisse por todo o território angolano e fosse finalmente reconhecido em 1974 pelas autoridades portuguesas, poucos meses antes da sua retirada do território angolano. ${ }^{3}$ Com a independência angolana, no entanto, os problemas não desapareceram para a Igreja Tocoísta: perseguida pelo regime de Agostinho Neto, voltou a sofrer perseguições e prisões políticas que apenas viriam a cessar no final da década de 1980. Esta "história de sofrimento" (Blanes 2009a) voltou, no entanto, a não constituir entrave para o estabelecimento da Igreja Tocoísta como uma das principais instituições religiosas da Angola contemporânea, com centenas de milhares de seguidores pelo país fora e com uma implantação por todo o seu território.

Apesar dessa resistência e vitalidade, a Igreja Tocoísta lutou, durante um período importante da sua existência, com a necessidade de "sobreviver a profecia" - ou seja, teve de se adaptar a processos de mudança social que de certa forma puseram em causa as condicionantes sob as quais se originou: o fim da "situação colonial" (Balandier 1955); a sua inserção numa Angola pós-colonial marcada pelo conflito militar e, posteriormente, pela "reconstrução da nação" na paz; a sua "extraversão" (Bayart 2000) geográfica e identitária através de processos de transnacionalização; e, em especial, o desaparecimento físico do seu profeta fundador e o correspondente processo de transição geracional.

Um profeta é, no essencial, um "meio" através do qual uma mensagem divina ou espiritual é transmitida para o meio físico. No entanto, como já foi

3 De forma contraproducente com os objetivos que motivaram a sua estratégia, a PIDE acabaria por participar involuntariamente na "expansão tocoísta" pelo território angolano, já que, quando recebeu o grupo de "deportados" liderado por Simão Toco, optou por distribuí-los em distintos campos de trabalho de norte a sul de Angola, na expectativa de ver a dissolução do movimento. Como consequência, Toco e seus seguidores conseguiram proselitizar nas distintas províncias e assim tornar a Igreja Tocoísta um movimento "nacional angolano" (Blanes 2009a). 
frequentemente discutido na literatura sobre o tema (ver Walker 1979), os profetas frequentemente aparecem como o meio e, simultaneamente, como a mensagem. $\mathrm{Na}$ igreja aqui em causa, o desaparecimento físico de Simão Toco exponenciou um problema de sucessão, traduzido em conflitos violentos entre distintos protagonistas, setores e alianças. Estes conflitos são de uma complexidade difícil de resumir num artigo científico. ${ }^{4}$ No entanto, começaremos por referir que, entre outras coisas, esses conflitos têm muito a ver com problemas de geração, memória e presença: são percetíveis divisões entre membros da comunidade religiosa em causa que se recordam efetivamente da "presença" do profeta entre eles e aqueles que não a lembram - mas que em alternativa reinventam novas maneiras de o tornar "presente" nas suas vidas e atividade religiosa.

Neste caso concreto, falamos apenas da diferença de uma geração, já que o profeta desapareceu recentemente (em 1984) e persiste uma memória física e visual do mesmo que é fundamental no seio da igreja - pelo menos quando comparado com o caso kimbanguista, da presença de cujo profeta, Simon Kimbangu (que faleceu em 1951, tendo ainda por cima permanecido os últimos 30 anos da sua vida em prisão), resta pouca evidência material. ${ }^{5} \mathrm{E}$, no entanto, a divisão é mais óbvia do que no caso kimbanguista: na situação atual, a Igreja Tocoísta encontra-se dividida em vários grupos, sendo um dos principais o chamado grupo dos "Doze Mais Velhos" - que defende, perante uma geração de tocoístas que assumiram a liderança através da criação da chamada "Direção Universal", ser o portador da herança do profeta original, já que é ali que se encontram os sobreviventes e descendentes do grupo que começou a seguir Toco na década de 1940. Hoje, em Angola e na diáspora angolana, a ala "Universal" é, do ponto de vista demográfico, mediático e financeiro, a hegemónica. Mas persiste em qualquer caso uma dimensão conflitiva que envolve em particular o problema da memória do profeta, da sua trajetória biográfica e dos seus ensinamentos: frequentemente ouvimos falar, nestes conflitos, de acusações de "apagamento", "manipulação" ou "reescrita" da história tocoísta, mediadas pela legitimação política da questão geracional (Blanes 2014). Noutras palavras, uma disputa sobre "quem detém o tocoísmo verdadeiro" após o desaparecimento de Simão Toco.

Mas existe neste contexto uma outra lógica que participa nestas disputas e divisões: a evolução de uma agência político-religiosa localmente inscrita que

4 Já fizemos tentativas parciais de explicação dos acontecimentos noutros lugares (Blanes 2009a). Para o caso da Igreja Kimbanguista, ver Sarró, Blanes e Viegas (2008).

5 Referimo-nos aqui a fontes arquivísticas e audiovisuais que registam a vida e pessoa do profeta. No caso de Simão Toco, existe um impressionante e considerável acervo documental "recolhido" pela PIDE, que inclui fotografias, cartas pessoais, relatórios policiais, entrevistas, etc. (ver Blanes 2011 a, 2014). No caso de Simon Kimbangu, apenas resta uma imagem fotográfica e a memória dos seus ditos e feitos que foi "transportada" pelos seus três filhos (entretanto falecidos) e netos. 
motivou o aparecimento de ambos os movimentos para um processo de instalação transnacional e diaspórico que os marcou a partir da década de 1980 (ver Blanes 2008; Sarró 2009). Este desenvolvimento certamente complexificou as dinâmicas de geração, presença e memória no que diz respeito a uma experiência religiosa profética. Nas páginas que se seguem, procuraremos descrever os processos sociológicos e institucionais que motivaram estes conflitos e correspondentes exercícios de memória.

\section{RELIGIÃO E PROFETISMOS NA ANGOLA CONTEMPORÂNEA E SUA DIÁSPORA}

$\mathrm{Na}$ sociedade angolana de hoje, a religião (e em particular o cristianismo) atingiu uma centralidade impensável nos anos anteriores ao armistício. Luanda é hoje uma das cidades com maior índice de locais de culto no continente africano, e a religião assume um papel cada vez mais visível e politicamente ativo no território nacional. $\mathrm{Na}$ capital, se musseques famosos como o Palanca albergam igrejas praticamente em cada rua (Pereira 2004), outras áreas como o Golfe ostentam grandes catedrais de diversos movimentos cristãos, como a antiga Igreja Maná, a Igreja Universal do Reino de Deus, o Exército de Salvação e outros - para além, obviamente, das igrejas Kimbanguista e Tocoísta. Apesar de muitas destas igrejas terem aparecido na década de 1990, hoje em dia verifica-se a sua "explosão" na esfera pública, de forma tão impactante que o seu mero mapeamento se revela como uma tarefa ciclópica (ver Viegas 1999, 2007). A título de exemplo, segundo um dos últimos levantamentos quantitativos levados a cabo pelo INAR (Instituto Nacional para os Assuntos Religiosos), em 2007 contabilizavam-se 84 igrejas legalmente reconhecidas e 729 a aguardar reconhecimento (ver Viegas 2007).

Esta situação contrasta com a de décadas anteriores, em que a questão religiosa se encontrava (eufemisticamente) "mediada” pela opção e intervenção dos regimes governativos. Se durante grande parte da época colonial a hegemonia católica convivia com a presença minoritária e dispersa de missões protestantes que começaram a disseminar-se no país desde o século XIX, ${ }^{6}$ nos primeiros anos após a independência de 1975 a "mediação" do governo do MPLA de Agostinho Neto passou pela proibição de todo e qualquer culto religioso e correspondente apropriação do património e bens religiosos (nomeadamente

6 Ver Freston (2001). A relação entre Igreja Católica, missões protestantes e o projeto colonial português, frequentemente retratada em termos de poder e contrapoder, é discutida, por exemplo, por Didier Péclard (1998a) e David Birmingham (1998). No caso particular das missões batistas, verifica-se a sua entrada em território angolano a partir do Congo Belga na década de 1870, com particular incidência no Baixo Congo e no Norte de Angola - precisamente onde nasceram Simon Kimbangu e Simão Toco. Ambos frequentaram na sua juventude as missões batistas. 
da Igreja Católica, principal "parceira" do governo colonial português). ${ }^{7}$ Tal decorria da implementação de um "ateísmo militante" de inspiração soviética na ideologia e pragmática do partido do poder e que reverteu numa "privatização" do movimento tocoísta em particular, dados os desentendimentos entre o primeiro presidente angolano, Agostinho Neto, e o profeta Simão Toco (Blanes 2014). A situação começou a infletir já na década de 1980, quando o gabinete de José Eduardo dos Santos começa a promover campanhas de reconhecimento legal que, independentemente do controlo estatal a que as instituições estavam sujeitas, permitiram entre outras coisas a instalação progressiva de um cenário religioso plural (Schubert 1999, 2000). Se, na primeira campanha de 1987, apenas a Igreja Católica e outros 11 movimentos religiosos viram o seu estatuto restabelecido (e consequentemente, no caso do catolicismo, bens e património devolvidos), no segundo momento, em 1992, várias dezenas de outros movimentos foram oficialmente reconhecidos - entre eles, a Igreja Tocoísta. ${ }^{8}$

A década de 1990 viria a significar um momento de autêntica explosão de expressões religiosas em Angola. Em grande parte graças à entrada em território angolano de igrejas de origem estrangeira, sobretudo filiadas no ramo evangélico e pentecostal ou neopentecostal (ver Freston 2005). Casos como o da entrada de instituições oriundas do espaço lusófono transnacional, como a Igreja Maná ou a Igreja Universal do Reino de Deus, revelam novas processualidades, como sejam as relações transnacionais que se desenvolvem no espaço atlântico meridional através de percursos distintos dos de tempos coloniais (Sarró e Blanes 2009). Nos dias de hoje, a palavra de ordem é outra: a da participação eclesiástica nos processos de reconciliação e reconstrução nacional (ver Schubert 2000; Messiant 2008).

Neste panorama, religióes proféticas como o kimbanguismo e o tocoísmo assumem um lugar altamente simbólico e particular, a começar pelo facto de ambas terem tido origem no âmbito de movimentos de contestação aos projetos coloniais, e a sua participação (espiritual ou efetiva) nos movimentos de libertação congolês e angolano é frequentemente discutida. No caso tocoísta, esta associação com o nacionalismo angolano pode ser classificada como "ambígua" e "não resolvida" do ponto de vista do consenso teórico (ver, por exemplo, Pélissier 1978; Fernando 1995; Grenfell 1998; Gonçalves 2003; Paxe 2009). Por um lado, as mensagens e discursos de Toco foram, desde o primeiro momento, de orientação anticolonial e a promulgar a libertação espiritual do africano - postura que o levou a ser em primeiro lugar expulso do Congo Belga

7 Isto apesar de, como descreve Didier Péclard, os principais protagonistas políticos do nacionalismo angolano - Agostinho Neto, Jonas Savimbi e Holden Roberto - terem um background religioso (Péclard 1998b).

8 Nesta altura, já a igreja se encontrava em pleno conflito, pelo que foram reconhecidas três "Igrejas Tocoístas" diferentes (Viegas 2007; Blanes 2009a). 
e posteriormente, já em território angolano, exilado por ordem da PIDE em Ponta Albina, no Namibe (1950-1960) e, finalmente, em São Miguel, nos Açores (1963-1974). É igualmente sabido que muitos angolanos aderiram ao movimento de Simão Toco por se identificarem com a sua mensagem emancipatória e libertária (Blanes 2014). Por outro lado, no espírito reformista da doutrina que promulgava, Toco proibia os seus seguidores de tomar partido político e de pegar em armas - facto que levou à posterior recriminação e ressentimento de ambos os lados da contenda (Grenfell 1998). Por último, o facto de Toco, antes do seu exílio nos Açores, ter sido utilizado pelo regime português para "desmobilizar" os seus conterrâneos em pleno levantamento no Uíge (Grenfell 1998) levou a que crescesse a desconfiança política em relação à sua pessoa. Várias declarações entretanto feitas a meios de comunicação portugueses, marcadamente pró-colonialistas, fomentaram a ambiguidade pública da figura do profeta (Blanes 2014).

Esta situação levou a que, tal como referimos acima, nos primeiros anos após a independência o movimento tocoísta voltasse a ser perseguido pelas autoridades (desta vez) angolanas. Aliás, quando regressou do exílio nos Açores em 1974, Simão Toco chegou a Luanda apelidado de "homem de paz" (Kisela 2004), com a firme vontade de participar, enquanto "interlocutor apartidário" e com base na ética e moralidade cristãs, nas negociações para a formação do primeiro governo nacional angolano. Mas essa intenção não só não impediu o início da guerra civil em Angola, como também implicou fortes recriminações dos partidos políticos envolvidos nas negociações (MPLA, UNITA, FNLA), que, por sua vez, motivaram medidas de repressão contra os tocoístas até à data da morte de Simão Toco em 1984, num processo conhecido dentro da igreja como "as segundas prisões do profeta" (sendo as primeiras as verificadas no Congo Belga em 1950). ${ }^{9}$ Produzia-se, então, um "desencaixe" entre o projeto espiritual libertário e unificador de Simão Toco e o panorama partidário fracionado da Angola pós-independência. Esse desencaixe, em última instância, produzia-se finalmente entre o tocoísmo, cujo líder era uma figura pública proeminente na sociedade angolana, e o "partido" do poder, o MPLA, estruturado em torno de pragmáticas divergentes de liderança política e religiosa. ${ }^{10}$

No entanto, numa observação a posteriori, também se percebe como, apesar das ambiguidades, o tocoísmo, pelo mero facto de ter sido uma igreja que "participou" na génese do nacionalismo angolano, e cujo líder era um profeta conterrâneo que resistiu ao domínio colonial, acumulou um sentimento de

9 É sabido, aliás, que Simão Toco e Agostinho Neto eram amigos de infância, na altura em que Toco estudava no Liceu Salvador Correia em Luanda (Kisela 2004). Esta postura de Toko durante as negociações, recusando-se a tomar partido pelo MPLA, terá posto fim a essa amizade.

10 Referimo-nos aqui, em particular, ao contexto de Luanda, onde se concentravam as principais lideranças, tanto do lado partidário como eclesiástico. 
orgulho patriota que o diferencia da grande maioria de movimentos cristãos nesse país. É, de acordo com os seus crentes, a única "igreja de raiz angolana" e a única, para além da Igreja Católica, com uma implantação territorial alargada que abarca todas as províncias do país. Mas a este reconhecimento junta-se outro ainda: o facto de, a partir de 1992 - altura em que é inaugurada a primeira Igreja Tocoísta na Europa, em Lisboa, da mão de um grupo de crentes entretanto imigrados nesta cidade (Blanes 2009a, 201 lb) -, a igreja se converter num fenómeno de transnacionalização cristã de sul para norte, a única igreja de origem angolana que "exportou" a sua fé para fora do país.

O aparecimento de uma Igreja Tocoísta em território europeu encerra simultaneamente algumas continuidades e contradições. Por um lado, surge como consequência natural de um processo demográfico de constituição de uma "diáspora angolana" em território europeu nas décadas de 1980 e 1990 (Blanes 201 lb); desta perspetiva, o aparecimento de uma congregação em Lisboa seria até expectável, tendo igualmente em conta a participação angolana nos processos de reconfiguração pluralizada do panorama religioso português (Blanes 2008, 2009b; Sarró e Santos 2011; Sarró e Mélice 2010). Por outro lado, a igreja também surge numa direcionalidade contrária ao movimento sócio-histórico observado na mesma altura em Angola: enquanto em Luanda a igreja experienciava um processo de tumulto e desagregação, na Europa verificava-se um processo de disseminação e expansão - que, entre outras coisas, levou a que a partir de Lisboa se promovessem redes de evangelização e congregação tocoísta em outras cidades europeias (Blanes $201 \mathrm{lb}$ ). Verificava-se, então, uma autonomia entre ambos os processos. E sobretudo produzia-se uma desterritorialização que redundou numa noção até então inédita: a configuração de uma "diáspora tocoísta", com as adjacentes perceções complexificadas de geração, presença e memória.

Neste âmbito, esta igreja representa um exemplo paradigmático de transformação e vitalidade religiosa que deixou de operar numa escala ou circunscrição regional, nacional ou sequer continental. Se um importante corpo bibliográfico e teórico das décadas de 1960 e 1970 conectava, em tempos coloniais, formas emergentes de cristianismo ao problema da opressão sociopolítica e à luta pela libertação, também é verdade que, no contexto pós-colonial, a imaginação religiosa (e em particular cristã) em África se revelou de uma criatividade e inovação que de certa forma relativiza (sem, obviamente, a tornar irrelevante) a questão da opressão. Este ato propiciou o aparecimento de novos paradigmas teóricos no estudo do cristianismo africano - por exemplo, as propostas de John e Jean Comaroff e seus seguidores, que ligaram novas formas de cristianismo à emergência de um "capitalismo milenar", neoliberalismo, exclusão da juventude, políticas de acusação, etc. (ver, por exemplo, Comaroff e Comaroff 2000), ou o crescente interesse pelos trajetos de disseminação transnacional dos distintos movimentos contemporâneos (ver Bruijn, van Dijk e Foeken 2001). 
Efetivamente, as particularidades do "cristianismo globalizado" dos séculos XX e XXI criaram uma situação onde, tal como argumenta o historiador Philip Jenkins, o "cristão comum de hoje vive no Congo ou no Brasil" (2002: 58; ver também 2007), ou, como nos explica a socióloga Grace Davie (2002), no que diz respeito à religião contemporânea, a Europa é "uma exceção". Se, por um lado, não podemos negar a importância da "instituição" cristã na promoção de sujeitos coloniais fora da metrópole, também é verdade que esta subjetividade se encontra hoje a viajar em sentido inverso (em direção à Europa) e a redefinir noções de tradição, pertença ou mesmo de cidadania. Portanto, falamos aqui de pessoas que vivem com uma herança compósita: um cristianismo global, uma cultura local e uma relação histórica com a Europa (e, em particular, com Portugal) e o outro lado do Atlântico, uma experiência migratória e, finalmente, uma consciência universalizante da pessoa, da humanidade e da cidadania.

Assim, igrejas proféticas como o tocoísmo apresentam-se neste contexto como alternativas aos paradigmas clássicos sobre o cristianismo africano. O paradoxo entre o paradigma de repressão, que "explicava" a emergência de movimentos cristãos proféticos e independentes em África, e o movimento de "extraversão" (Bayart 2000) de igrejas cristãs para fora de África (Palmié 2007) é particularmente evidente em igrejas como a Kimbanguista, a "Igreja dos Negros em África” de Simon Mpadi, ou o “amicalismo” de André Matsoua, que floresceram na época colonial e motivaram numerosos estudos etnográficos que associaram a sua emergência àquilo que Balandier chamava "situação colonial" (1955) e à procura da libertação, através de "sonhos milenaristas" e da ação de um profeta carismático, dos povos oprimidos. A contextualização, obviamente, fazia todo o sentido; no entanto, hoje, em plena era pós-colonial, verificamos que muitos destes movimentos não só não desapareceram como se transformaram e institucionalizaram em grandes movimentos de alcance internacional. ${ }^{11}$

No entanto, existe a convicção mais ou menos generalizada, entre os autores que trabalham sobre movimentos cristãos na África Subsariana, de que muitas destas igrejas proféticas que mostravam efervescência e agência nos tempos coloniais foram hoje de certa forma suplantadas pelo appeal dos movimentos pentecostais, neopentecostais e carismáticos e perderam a sua razão de ser no mercado espiritual da ex-colónia. No entanto, as igrejas proféticas sobrevivem - e não só em África, mas também na diáspora africana, nas Américas, etc.

ll Seria impossível oferecer neste espaço uma visão global da literatura sobre movimentos proféticos na época colonial em África. Para além da lista interminável de monografias, houve algumas tentativas de análise de conjunto. Vejam-se, a título de exemplo, os review articles de Dozon (1974), Balandier (1976), Fernandez (1978) e Ranger (1986), entre outros (ver também Sarró 2009: cap. 1). Sobre os problemas de "definição de um profeta" e o uso transcultural da categoria, ver Johnson e Anderson (1995). 
Para além da mera sobrevivência, também se observa a criatividade, a transformação e o conflito. Vejamos estes processos através do exemplo tocoísta.

\section{OS DOZE CONTRA O CARISMA:}

\section{CONFLITO E SUCESSÃO NA IGREJA TOCOÍSTA}

Como referimos acima, depois do seu regresso a Angola em 1974, Simão Toco conheceu um período difícil de perseguições e prisões. Como resultado, a sua saúde deteriorou-se, levando ao seu falecimento por uma complicação cardiovascular na passagem de ano entre 1983 e 1984. Depois da sua morte, instalou-se um processo de sucessão na igreja. Disputas entre diferentes setores da liderança, iniciadas ainda antes do desaparecimento físico do profeta, levaram a que a situação não chegasse a bom termo, produzindo-se várias cisões no seu interior. ${ }^{12}$ Apareceram vários grupos em confronto mútuo, que afirmavam a sua legitimidade e liderança, sendo os principais os seguintes: a chamada "Direção Central", um primeiro grupo que derivava da cúpula diretiva em exercício no momento do falecimento do líder; os chamados "Doze Mais Velhos", grupo composto por sobreviventes e descendentes do núcleo inicial que seguira Simão Toco desde Léopoldville; um terceiro grupo, apelidado "18 Classes e 16 Tribos" (e posteriormente "Igreja Mundial"); e um quarto grupo, conhecido como "Palanca/Prenda" ou "Mboma", liderado por um sobrinho do profeta, Temo António. Destes, apenas os três primeiros foram oficialmente reconhecidos na ronda de legalização de 1992, desenvolvendo uma coexistência simultânea e reivindicando por separado a sua legitimidade enquanto herdeiros do movimento original. Por estar associada à cúpula dirigente no momento em que Toco faleceu, a "Direção Central" viria a constituir-se como o grupo quantitativamente mais significativo.

Nestes anos, o nível de conflito foi crescendo, com acusações públicas lançadas mutuamente e episódios de confrontos violentos. Um momento particularmente marcante foram as confrontações físicas entre tocoístas de uma das fações e elementos da segurança angolana, no dia 15 de fevereiro de 1987 na região de Catete, perto de Luanda. O confronto acabou com a intervenção da polícia e com dezenas de mortes. ${ }^{13}$

Portanto, o sentimento prevalente na década de 1990 era o de que a igreja poderia estar a conhecer os seus derradeiros momentos. Simultaneamente, começaram a surgir diversos relatos sobre aparições do "espírito" de Simão Toco a vários crentes, sempre com uma mensagem semelhante: a de que a

12 De acordo com o recolhido em várias entrevistas realizadas em Luanda, os pretextos para essa disputa inicial prendiam-se com aspetos de gestão financeira e institucional. Pouco antes de falecer, Simão Toco expressava o seu descontentamento com a situação, estando consciente de que após o seu desaparecimento "entrariam lobos no seu curral" (Agostinho s. d.: 82).

13 Entrevista com o bispo Afonso Nunes, a 3 de dezembro de 2007. Ver também Paxe (2009). 
igreja deveria reunificar-se. Foi o caso, por exemplo, de Fernando Tchiwale (que posteriormente viria a ser conhecido na igreja como "o Mensageiro"), o qual, oriundo do Capelongo (Huíla), chegou a Luanda em 1996 para visitar as distintas lideranças tocoístas, com a seguinte mensagem: o profeta pretendia voltar à Terra, mas não sabia onde se encontrava a sua casa, tendo em conta as separações vigentes (Quibeta s.d.; Blanes 2009a). A sua mensagem não convenceu os líderes de imediato, e Tchiwale permaneceu em Luanda durante alguns anos a tentar convencê-los.

No entanto, no ano 2000, um acontecimento mudou o panorama por completo: um jovem chamado Afonso Nunes, oriundo da região natal do profeta (Uíge), chegou a Luanda pela mão do grupo de vates da sua igreja local. ${ }^{14}$ Diziam que Nunes tivera uma série de sonhos onde lhe aparecia Simão Toco, e num deles o profeta "personificara" o seu corpo - significando isto que o espírito de Toco, após ter deixado o mundo físico em 1984 e se ter dirigido ao Céu, voltou a descer à Terra para habitar o corpo de Nunes, que por sua vez deixava de existir enquanto individualidade. Este processo de incorporação - referido no seio da igreja como "revestimento espiritual" ou "personificação" vinha acompanhado de uma mensagem/missão tripla: em primeiro lugar, deveria reunificar a igreja; em segundo, deveria construir uma "casa" para ele - nomeadamente o templo central da igreja, atualmente em fase de conclusão; finalmente, deveria "universalizar" a igreja, tornando efetiva a denominação de "Igreja no Mundo".

Após a chegada a Luanda, Nunes, passando a ser referido como "Simão Toco regressado", reuniu-se, tal como fizera o Mensageiro, com as distintas lideranças. O próprio Tchiwale reuniu-se com ele, e ambos concluíram que a pessoa que falara com ele em 1996 era a mesma que falara com Nunes em 2000 , e portanto aceitou a sua proposta. O mesmo aconteceu com a liderança da Direção Central: Luzaísso Lutango, anterior líder, aceitou deixar o cargo para Nunes, que assim deu início ao cumprimento das três mensagens - procedendo à tentativa de reunificação, à inauguração de uma "Direção Universal" e ao início da construção do Templo Universal no bairro do Golfe, em Luanda. Hoje, esse templo encontra-se perto da sua inauguração, ameaçando ser um dos maiores templos cristãos do continente africano.

No entanto, a tarefa da reunificação não se afigurava fácil. Com o tempo, conseguiu que os grupos do Palanca/Prenda e (parcialmente) 18 Classes e 16 Tribos aceitassem reunir-se. No entanto, o mesmo não foi possível com os Doze Mais Velhos. Tal como acontecera com os outros grupos, houve uma reunião entre as partes, mas na mesma os mais velhos não "reconheceram" Simão Toco na pessoa de Afonso Nunes.

14 Os vates ou vaticinadores são profetas na Igreja Tocoísta, pessoas imbuídas de possessão espiritual e carisma e com a capacidade de profetizar e curar. 
Quando entrevistámos, em 2008, os Doze Mais Velhos em Luanda, apercebemo-nos da importância crucial da "presença" para a memória e transmissão religiosa no seio da igreja. Explicaram-nos que não acreditavam que Afonso Nunes pudesse ser Simão Toco, não porque rejeitassem aprioristicamente a possibilidade do milagre e reincarnação, mas porque esse Simão Toco era muito diferente daquele que eles recordavam e mantinham presente na sua memória. Inclusive, contam, submeteram-no a uma série de interrogações acerca de eventos concretos vividos por eles com o profeta, para ver se era realmente a mesma pessoa. As respostas não os convenceram e portanto negaram que Nunes pudesse ser a reincarnação do seu líder.

Paradoxalmente, também é a "presença" o que explica o sucesso de Nunes entre as novas gerações de tocoístas em Luanda - pessoas que não querem apenas viver com a memória ou relatos distantes daquele grupo de anciãos que conheceram Simão Toco e que conseguem explicar, mas não reproduzir presencialmente, a excecionalidade do líder espiritual. Dir-se-ia que precisam de uma proximidade carismática, um corpo presente, uma palavra pronunciada: necessitam do espírito, não da recordação.

Nunes, na sua performatização convincente de um Toco personificado através de uma "extensão biográfica", "satisfaz" essa necessidade espiritual, ao ponto de ter revitalizado a Igreja Tocoísta de uma forma inédita e mais efetiva que entre o grupo dos Doze Mais Velhos, que se apresenta como numericamente minoritário nos dias de hoje. O discurso dos Doze Mais Velhos, para além de impressionante, é no entanto pouco efetivo do ponto de vista pragmático - tal como deveria ter sido a "recordação do mestre" para os discípulos de Jesus, que não o souberam imitar até que, segundo é contado nos Atos dos Apóstolos (2: 1-31), o Espírito Santo desceu sobre eles e assim puderam recriar (e não apenas recordar) a atividade milagrosa do líder.

Uma destas "presentificações" de Nunes tem a ver com a sua progressiva presença no território europeu, coordenando in loco o processo de expansão transnacional da igreja (entretanto ramificado para outros países da África Subsariana e para o Brasil). Esta presença não só permitiu incorporar a "experiência diaspórica tocoísta" no universo da igreja a partir de uma perspetiva afrocêntrica, mas também reapropriar uma parte da história tocoísta, ao reaproximar um território (Portugal) outrora configurado como remoto e inimigo. Em qualquer caso, também tornou "visível" uma liderança profética, perante núcleos de seguidores que cresceram numa experiência remota do tocoísmo (e de África).

Obviamente, não podemos reproduzir aqui todos os elementos necessários para contextualizar do ponto de vista religioso e político o grande êxito (imediato e, desde então, galopante) de Nunes através da personificação de Simão Toco (ver Blanes 2010, 201 la, 2014). Como é que Nunes conseguiu ter "sucesso", do ponto de vista material e do número de seguidores, onde antes 
outros falharam? ${ }^{15} \mathrm{O}$ que nos interessa neste ponto é realçar a dialética entre a ausência e a presença do espírito (e no espírito), e como essa presença/ausência é conjugada com a inovação espiritual e geracional de um movimento religioso (ver, a título comparativo, Engelke 2007).

\section{AS DIALÉTICAS DA PRESENÇA E DA AUSÊNCIA}

A chegada e instalação de Afonso Nunes em Luanda pode ser objeto de várias leituras. Uma leitura política poderia sugerir que a restauração do tabernáculo seria uma forma de "completar" o processo de rotinização e sobrevivência à profecia através de uma reivindicação particular de legitimidade.

No entanto, a sua invocação de uma "extensão biográfica" também pode ser lida como uma tentativa de "tornar presente" - no sentido sugerido por Matthew Engelke (2007) - uma experiência religiosa concreta: a de uma liderança e seguimento profético. Neste contexto, o que o caso tocoísta nos revela é uma dependência da presença física do profeta, e não apenas da sua mensagem. Lutam contra a burocratização e rotinização da memória, e "precisam" da presencialidade do carisma do líder (e não da sua representação por outrem).

Ao mesmo tempo, os tocoístas não pretendem ser vistos como "idólatras", na medida em que não se trata de adorar o profeta, mas sim Deus. De certa forma, o profetismo encara um problema semelhante ao do fetichismo: o problema da ambivalência e "presentificação do invisível" (para usar as palavras de Vernant) através de seres intermédios, sejam materiais ou humanos. Historiadores (Brown 1981; Vernant 1996 [1983]), psicólogos (Freedberg 1989), historiadores da arte (Morgan 2005; Belting 2007), filósofos (Steiner 1989; Gumbrecht 2004), antropólogos culturais (Napier 1986; Berliner 2007; Højbjerg 2007; Holbraad 2007) e outros também têm vindo a oferecer explicações sobre como objetos na sua materialidade (máscaras, fetiches, ícones, estátuas, ídolos) podem ser interpretados pelos crentes como agentes que incorporam uma realidade espiritual e não material.

Estamos, de facto, perante um puzzle, que se complexifica ainda mais quando estamos a falar de profetas. A ambivalência da representação, que Jack Goody atribuiu a objetos materiais e que, de acordo com ele, explica porque é que o iconoclasmo está tão presente em "sociedades fetichistas" (Goody 1991), também pode ser aplicada a pessoas. Aliás, como pode um ser humano ser considerado "não humano" por aqueles que o rodeiam? A resposta a esta pergunta talvez extravase a dimensão racional. Mas, seja como for, o profeta é

15 Antes de Nunes, houvera outros crentes tocoístas que afirmavam ter sido visitados pelo espírito de Simão Toco, que pretendia assim “descer à Terra" (ver Blanes 2009a, 2010, $2011 \mathrm{la}$ ). Mas também é verdade que, do ponto de vista émico, essa categoria de "sucesso" também é altamente contestada. Uma das políticas de Nunes mais criticadas pelos seus refratários tem sido precisamente a sua aproximação e relação de parceria com o governo angolano. 
tão "Janus" e fronteiriço como a máscara, e a sua legitimidade é forçosamente volátil. Tal como a máscara, outrora a materialização de um espírito, pode facilmente ser transformada num mero objeto e atirada para uma fogueira iconoclasta sem reparo, também o profeta pode facilmente perder o carisma e ser acusado de "falso profeta": a sua presença deixa portanto de ser divina e é reenquadrada como uma "deceção". Nesta perspetiva, Nunes/Toco é um profeta real (uma "presença real”, para usar as palavras de Steiner) para os seus seguidores, mas um farsante para os seus detratores.

Poder-se-ia argumentar que estamos a desenvolver um argumento demasiado ambicioso sobre a presença profética, quando de facto muitos tocoístas vivem muito longe do bispo Nunes/Toco e talvez nunca o tenham visto em pessoa. É verdade, mas também o é que Simão Toco, para além dos vários momentos de prisão e detenção, dirigiu a igreja durante 11 anos desde o exílio num farol remoto dos Açores (Blanes 2009a), longe da vista dos seus seguidores, tornando-se assim um "líder remoto" para muitos deles. Sob este ponto de vista, a própria história da Igreja Tocoísta pode ser entendida como uma constante reprodução geracional de presenças e ausências - e o desenvolvimento de uma experiência tocoísta diaspórica não seria senão mais uma das expressões de deslocamento, desterritorialização e pertença que afetam a conjugação tocoísta entre presença e memória. O conflito entre os Doze e a Direção Universal revela apenas uma das dinâmicas de tensão em jogo: o problema político e experiencial da "detenção da autoridade", que produz o debate sobre ortodoxia e heterodoxia (ou entre conservadorismo e inovação) entre distintos setores da igreja. Noutras palavras: quem "detém" a verdadeira memória do profeta Simão Gonçalves Toco, quando subsistem vários métodos e lógicas de apropriação da mesma? ${ }^{16}$ Nesta perspetiva, o problema da ausência do profeta encontrou soluções diferentes em distintos campos dos "herdeiros tocoístas". $\mathrm{E}$ as definições de testemunha, reprodução e iconoclasmo geracional (Sarró 2009) derivam dessas distintas soluções.

Mas o encobrimento do profeta não impede o facto de a sua presença ser real. Provavelmente até funciona na mesma lógica: reforça a imaginação sobre a "realidade" do profeta, tal como a esperança messiânica de que um dia ele estará presente em todo o mundo.

16 Este é uma dos pontos de friç̧ão em causa, mas não o único. Por outro lado, não pretendemos veicular a falsa ideia de que os Doze são os "conservadores" e a Direção Universal os "inovadores". Existem movimentos de ambas as tendências em ambos os lados. 


\section{BIBLIOGRAFIA}

AgOstinho, Pedro António, s.d., Simão Gonçalves Toco e os Tocoístas no Mundo. Luanda, edição de autor.

BALANDIER, Georges, 1955, Sociologie actuelle de l'Afrique Noire. Paris, Presses Universitaires de France.

BALANDIER, Georges, 1976, "Les mouvements d'innovation religieuse en Afrique Noire", em H.-C. Puech (ed.), Histoire des religions, vol. 3. Paris, La Pléiade, 1273.

BAYART, Jean-François, 2000, "Africa in the world: A history of extraversion", African Affairs, 99: 217-267.

BELTING, Hans, 2007, La vraie image: Croire aux images?. Paris, Gallimard.

BERLINER, David, 2007, "When the object of transmission is not an object: A West African example (Guinea-Conakry)", Res: Anthropology and Aesthetics, 51: 87-97.

BIRMINGHAM, David, 1998, "Merchants and missionaries in Angola", Lusotopie, 1998: 345-355.

BLANES, Ruy Llera, 2008, "Um cemitério chamado Europa: cristianismo, consciência global e identidades migratórias”, em R. do Carmo, D. Melo e R. Blanes (orgs.), A Globalização no Divã. Lisboa, Tinta da China, 317-333.

BLANES, Ruy Llera, 2009a, "Remembering and suffering: Memory and shifting allegiances in the Angolan Tocoist Church", Exchange: Journal for Missiological and Ecumenical Research, 38 (2): 161-181.

BLANES, Ruy Llera, 2009b, "Circunscrição moral: Mobilidade, diáspora e configurações doutrinais na Igreja Tokoísta”, em R. do Carmo e J. Simões (orgs.), A Produção das Mobilidades: Redes, Espacialidades e Trajectos num Mundo em Globalização. Lisboa, Imprensa de Ciências Sociais, 247-261.

BLANES, Ruy Llera, 2010, “The personification of a prophet: leadership, charisma and the globalization of the Angolan Tokoist Church", em S. Fancello e A. Mary (orgs.), Chrétiens Africains en Europe: Prophetismes, pentecôtismes et politique des nations. Paris, Karthala, 69-91

BLANES, Ruy Llera, 2011 a, "Unstable biographies: The ethnography of memory and historicity in an Angolan prophetic movement", History and Anthropology, 22 (1): 93-119.

BLANES, Ruy Llera, 201 lb, "Double presence: proselytism and belonging in an Angolan Prophetic Church's diaspora”, Journal of Religion in Europe, 4 (3): 409-428.

BLANES, Ruy Llera, 2014, A Prophetic Trajectory: Ideologies of Place, Time and Belonging in an Angolan Religious Movement. Oxford e Nova Iorque, Berghahn.

BROWN, Peter, 1981, The Cult of the Saints: Its Rise and Function in Latin Christianity. Chicago, The University of Chicago Press.

BRUIJN, Mirjam, Rijk VAN DIJK, e Dick FOEKEN (orgs.), 2001, Mobile Africa: Changing Patterns of Movement in Africa and Beyond. Leiden, Brill.

COMAROFF, Jean, e John COMAROFF, 2000, "Millennial capitalism: first thoughts on a second coming", Public Culture, 12 (2): 291-343.

CUNHA, J. Silva, 1959, Aspectos dos Movimentos Associativos na África Negra, Volume II (Angola). Lisboa, Junta de Investigações do Ultramar.

DAVIE, Grace, 2002, Europe: The Exceptional Case. Parameters of Faith in the Modern World. Londres, Darton, Longman and Todd. 
DOZON, Jean-Pierre, 1974, "Les mouvements politico-religieux: syncrétismes, messianismes, néo-traditionalismes”, em M. Augé (org.), La construction du monde: religion, représentations, ideologie. Paris, F. Maspero, 75-111.

EISENLOHR, Patrick, 2009, "Technologies of the spirit: Devotional Islam, sound reproduction and the dialectics of mediation and immediacy in Mauritius", Anthropological Theory, 9 (3): 273-296.

ENGELKE, Matthew, 2007, A Problem of Presence: Beyond Scripture in an African Church. Berkeley, University of California Press.

FERNANDEZ, James W., 1978, "African religious movements", Annual Review of Anthropology, 7: 195-234.

FERNANDO, Manzambi, 1995, "A trajectória de Simão Gonçalves Toko e o tokoísmo no despertar da Consciência Nacional em Angola: Um contributo para a Luta de Libertação Nacional", em AAVV, Angola: 40 Anos de Guerra. Gaia, Sociedade de Estudos e Intervenção Patrimonial, 22-33.

FREEDBERG, D., 1989, The Power of Images: Studies in the History and Theory of Response. Chicago, The University of Chicago Press.

Freston, Paul, 2001, Evangelicals and Politics in Asia, Africa and Latin America. Cambridge, Cambridge University Press.

FRESTON, Paul, 2005, “The Universal Church of the Kingdom of God: a Brazilian church finds success in Southern Africa", Journal of Religion in Africa, 35 (1): 33-65.

GONÇALVES, António Custódio, 2003, Tradição e Modernidade na (Re)Construção de Angola. Porto, Afrontamento.

GOODY, Jack (org.), 1966, Succession to High Office. Cambridge, Cambridge University Press.

GOODY, Jack, 1991, "Icônes et iconoclasme en Afrique", Annales ESC, 6: 1235-1251.

GRENFELL, James, 1998, "Simão Toco: An Angolan prophet", Journal of Religion in Africa, 28 (2): $210-226$.

GUMBReCHT, Hans Ulrich, 2004, Production of Presence: What Meaning Cannot Convey. Stanford, NJ, Stanford University Press.

HØJBJERG, Christian Kordt, 2007, Resisting State Iconoclasm among the Loma of Guinea. Durham, NC, Carolina Academic Press.

HOLBRAAD, Martin, 2007, "The power of powder: Multiplicity and motion in the divinatory cosmology of Cuban Ifá (or mana again)", em A. Henare, M. Holbraad e S. Wastell (orgs.), Thinking through Things: Theorising Artefacts Ethnographically. Londres e Nova Iorque, Routledge, 189-225.

JENKINS, Philip, 2002, “The next Christianity”, The Atlantic Monthly, 290 (3): 53-68.

JENKINS, Philip, 2007, God's Continent: Christianity, Islam, and Europe's Religious Crisis. Oxford, Oxford University Press.

JOHNSON, Douglas H., e David M. ANDERSON, 1995, "Revealing prophets", em D.M. Anderson e D. H. Johnson (orgs.), Revealing Prophets: Prophecy in Eastern African History. Londres, Nairobi, Kampala e Athens, OH, James Currey, EAEP, Fountain Publishers e Ohio University Press, 1-27.

KISELA, Joaquim Albino, 2004, Simão Toco: A Trajectória de Um Homem de Paz. Luanda, Editorial Nzila.

MACGAFFeY, Wyatt, 1983, Modern Kongo Prophets: Religion in a Plural Society. Bloomington, Indiana University Press. 
MARTIN, Marie-Louise, 1974, Kimbangu: An African Prophet and His Church. Oxford, Blackwell.

MARY, André, 2008, "Introduction: Africanité et christianité, une interaction première", Archives de Sciences Sociales des Religions, 143 (3): 9-30.

MESSIANT, Christine, 2008, L'Angola Postcolonial. Paris, Karthala, 2 vols.

MORGAN, David, 2005, The Sacred Gaze: Religious Visual Culture in Theory and Practice. Berkeley, University of California Press.

NAPIER, A. David, 1986, Mask, Transformation, and Paradox. Berkeley, University of California Press.

PALMIÉ, Stephan, 2007, "Introduction: out of Africa?", Journal of Religion in Africa, 37 (2): 159-173.

PAXE, Abel Marcelino Vieira, 2009, Dinâmicas de Resiliência Social nos Dircursos e Práticas Tokoístas no Icolo e Bengo. Lisboa, ISCTE - Instituto Universitário de Lisboa, tese de mestrado em Estudos Africanos.

PÉCLARD, Didier, 1998a, “'Eu sou americano’: Dynamiques du champ missionnaire dans le planalto central angolais au XXe siècle”, Lusotopie, 1998: 357-376.

PÉCLARD, Didier, 1998b, "Religion and Politics in Angola: The Church, the Colonial state and the emergence of Angolan Nationalism, 1940-1961", Journal of Religion in Africa, 28 (2): 160-186.

PÉLISSIER, René, 1978, "A la recherche d'un dieu anti-colonialiste”, em R. Pélissier (org.), La colonie du Minotaure: nationalismes et révoltes en Angola (1926-1961). Orgeval, Editions Pélissier, 159-189.

PEREIRA, Luena Nascimento Nunes, 2004, Os Bakongo de Angola: Religião, Política e Parentesco num Bairro de Luanda. São Paulo, Universidade de São Paulo, tese de doutoramento em Antropologia.

QUiBetA, Simão Fernando, s.d., Simão Tôco: O Profeta Africano em Angola, Vida e Obra. Luanda, edição de autor.

RANGER, Terence O., 1986, "Religious movements and politics in Sub-Saharan Africa", African Studies Review, 29 (2): 1-69.

ROBBINS, Joel, 2004, "The globalization of Pentecostal and Charismatic Christianity", Annual Review of Anthropology, 33: 117-143.

SANTOS, Eduardo dos, 1969, Religiões de Angola. Lisboa, Junta de Investigações do Ultramar.

SARRÓ, Ramon, 2009, The Politics of Religious Change on the Upper Guinea Coast: Iconoclasm Done and Undone. Edimburgo, Edinburgh University Press for the International African Institute.

SARRÓ, Ramon, e Anne MÉLICE, 2010, “Kongo and Lisbon: The dialectics of 'centre' and 'periphery' in the Kimbanguist Church”, em Sandra Fancello e André Mary (orgs.), Chrétiens africains en Europe: prophétismes, pentecôtismes et politique des nations. Paris, Karthala, 43-67.

SARRÓ, Ramon, e Joana SANTOS, 2011 , "Gender and return in the Kimbanguist Church of Portugal”, Journal of Religion in Europe, 4 (3): 369-387.

SARRÓ, Ramon, e Ruy BLANES, 2009, "Prophetic diasporas: moving religion across the Lusophone Atlantic”, African Diaspora, 2: 52-72.

SARRÓ, Ramon, Ruy BLANES, e Fátima VIEGAS, 2008, "La guerre dans la paix: ethnicité et angolanité dans l'Eglise kimbanguiste de Luanda", Politique Africaine, 110: 84-101. 
SCHUBERT, Benedict, 1999, "Os protestantes na guerra angolana depois da independência”, Lusotopie, 1999: 405-413.

SCHUBERT, Benedict, 2000, A Guerra e as Igrejas: Angola, 1961-1991, Basel, P. Schlettwein Publishing.

STEINER, George, 1989, Real Presences. Chicago, The University of Chicago Press.

VERNANT, Jean-Pierre, 1996 [1983], “De la présentification de l'invisible à l'imitation de l'apparence", em Entre mythe et politique. Paris, Seuil, 359-377.

VIEGAS, Fátima, 1999, Angola e as Religiões. Luanda, edição de autor.

VIEGAS, Fátima, 2007, Panorama das Religióes em Angola: Dados Estatísticos 2007. Luanda, INAR - Instituto Nacional para os Assuntos Religiosos.

WALKER, Sheila S., 1979, "The message as the medium: Harrist churches of the Ivory Coast and Ghana”, em G. Bond, W. Johnson e S. S. Walker (orgs.), African Christianity: Patterns of Religious Continuity. Nova Iorque, Academic Press, 9-64.

WEBER, Max, 2006, Sociologia das Religiões. Lisboa, Relógio d’Água. 